\title{
LA ESCUELA PUBLICA EN MÉXICO Y LA DEFINICIÓN INCIERTA DE LA NACIÓN
}

\author{
INÉS CASTRO* \\ MÁrcia SMITH*
}

\begin{abstract}
RESÚMEN: La escuela en México siempre estuvo bajo el discurso de la integración, la homogenización y la construcción de la identidad nacional. El interés era dar continuidad a la cultura occidental europea, filtrada por las singularidades hispánicas y penetradas por el reconocimiento idealizado de lo autóctono (pueblos originarios). Sin embargo, el crecimiento de la pobreza, sumado a la permanencia de tendencias históricas discriminatorias en términos étnicos que se enfrentan al discurso cada vez más ampliado de respecto a los derechos humanos contraponen una realidad que invalida el logro de los objetivos originales de la escuela. En la última década surgen con fuerza las ideas de pluriculturalidad, como posiciones que desean integrar y renovar de alguna manera las propuestas escolares. Estas derivan del reconocimiento cada vez más expandido que se otorga a la diversidad cultural y de las deficiencias del proyecto del mestizaje cultural implementado en el país en períodos anteriores, que abogaba por una integración cultural casi "forzosa" que no resultó posible.
\end{abstract}

Palabras claves: México. Escuela. Diversidad. Mestizaje. Identidad.

* Licenciada en Ciencias de la Educación y investigadora del Instituto de Investigaciones sobre la Universidad y la Educación, Universidad Nacional Autónoma de México (UnAM). E-mail:micl@unam.mx

** Mestre em Sociología y investigadora del Instituto de Investigaciones sobre la Universidad y la Educación, Universidad Nacional Autónoma de México (UnAm). E-mail: marciasm@servidor.unam.mx 


\title{
PUbliC SCHOOL IN MEXICO AND THE UNCERTAIN DEFINITION OF THE NATION
}

\begin{abstract}
In Mexico, schools have always been part of the discourse on integration, homogenization and the construction of national identity. The main interest was to ensure continuity to the Western European culture, filtered through the Hispanic singularity and penetrated by the idealized recognition of the autochthonous (indigenous peoples). However, the growth of poverty and the permanent historical tendency to ethnic discrimination, as opposed to the widening discourse on human rights, have invalidated the achievement of the original school's goals. In the last decade, strong ideas of multiculturalism have arisen, which wish to integrate and renew school's propositions. These ideas derive from the increasing recognition of the expanding cultural diversity and of the shortcomings of the cultural mestizaje project implemented in the country in previous times, which advocated an almost "forced" cultural integration that was impossible.
\end{abstract}

Key words: Mexico. School. Diversity. Mestizaje. Identity.

\section{Introducción}

$\mathcal{E}$ n México, la inevitable percepción del crecimiento de la pobreza que tiene algunas de sus razones en los procesos de mundialización económica y también en la creciente concentración de la renta, sumada a la permanencia de tendencias históricas discriminatorias en términos étnicos enfrentadas al discurso cada vez más ampliado de respecto a los derechos humanos, contrasta y contrapone una realidad que invalida el logro de los anteriores objetivos originales de la escuela. La pobreza y la discriminación configuran tal realidad y algunos autores se cuestionan si la escuela ha alcanzado los objetivos que se propuso "asegurando la integración de la sociedad y la promoción del individuo" (Dubet-Martuccelli,1998, p. 73) y dejando "huellas de sus efectos directos e indirectos sobre numerosos aspectos de la vida de los individuos y las sociedades" (Baudelot-Leclercq, 2008, p. 19).

La escuela en México siempre estuvo bajo el discurso de la integración, la homogenización y la construcción de la identidad nacional. Frecuentemente se encuentra la preocupación de dar continuidad a la cultura occidental europea, filtrada por las singularidades hispánicas y 
penetrada por el reconocimiento idealizado de lo autóctono (pueblos originarios). ${ }^{1}$

En los procesos de construcción de la identidad nacional mexicana, donde participa la escuela, el concepto de latinidad se adopta en el entendido de identificarse con una realidad que aparece cercana y con una pretendida similitud que se valora: la nación se reconoce parte de Latinoamérica. Sin embargo, por varias razones, la idea de latinidad no expresa una creación intelectual autóctona que refleje las experiencias objetivas de construcción de una identidad colectiva en el país.

Históricamente, la idea de "latinidad" es una creación europea que se aplica para establecer un "conglomerado cultural" vinculado a países europeos distintos de los sajones. Específicamente, surge en Francia con Napoleón III frente a la expansión de EUA en el nuevo continente americano, pero obtendrá significativa difusión y apoyo de importantes intelectuales latinoamericanos en sus aspiraciones de edificar un Estado-nación que se identifique y se reconozca como parte del mundo occidental.

Hoy día, en el caso de la latinidad, y a partir de los análisis poscolonialistas que señalan las ataduras a intereses externos de los procesos sociales internos de las naciones latinoamericanas (incluso México), es posible darse cuenta que el citado concepto (Mignolo, 2007) generó un distanciamiento y abandono de las condiciones reales de existencia. De alguna manera, autoreconocernos en términos de latinidad y ser reconocidos bajo esa visión nos alejan de una identificación más genuina y vamos a gravitar más en el espacio de la soledad ${ }^{2}$ que en el del reconocimiento recíproco.

En México, las vertientes culturales, latinidad (occidentalización) y pueblos originales buscan una relación de equilibrio no siempre lograda en los procesos de construcción de una identidad cultural y nacional. La escuela mexicana, eje muy importante en la definición de una identidad colectiva, vivirá con frecuencia cambios en sus finalidades y características. Tales transformaciones ocurren en determinados momentos históricos donde suceden alteraciones en la vida política del país. Las motivaciones están atadas a movimientos sociales generados por la necesidad de resolver apremiantes problemas de desigualdad material y diversidad cultural y se suman a un desarrollo político pobre que no supera el autoritarismo, el protagonismo y el enfrentamiento entre los liderazgos tradicionales y su clientelismo. En algunos momentos, la 
educación y la escuela dirigen sus planes hacia poblaciones distintas con las orientaciones específicas correspondientes como, por ejemplo, la escuela primaria urbana y la enseñanza rudimentaria, pero en otros se definirá como una escuela única para toda la población. Como consecuencia se desarrollan diferentes propuestas según diversos períodos históricos para intervenir en los procesos de socialización y construcción de la nacionalidad que parecen ser siempre la preocupación más entrañable de la política educativa. Habrá momentos en que la preocupación por la nacionalidad y su centralidad en el discurso del mestizaje oculta la rígida estratificación social que se impone. El mestizaje se entendía como una característica ya presente y permanente de México.

Esta situación no está exenta de críticas y propuestas alternativas. En la última década surgen con fuerza las ideas de pluriculturalidad, multiculturalidad e interculturalidad, como posiciones que desean integrar y renovar de alguna manera las propuestas escolares. Son propuestas que derivan del reconocimiento cada vez más expandido que se otorga a la diversidad cultural en términos mundiales y a las deficiencias del proyecto del mestizaje cultural implementado en el país en períodos anteriores, que abogaba por una integración cultural casi "forzosa" que no ha resultado posible.

De todo esto resulta un diagnóstico poco alentador sobre el desempeño de las instituciones escolares en los últimos decenios. Por varias razones la escuela no pudo educar e integrar significativamente a los mexicanos, aun cuando se tenía claro el modelo de sociedad que se quería construir (algo semejante a un Estado democrático de bienestar), y menos aún se vislumbra sus posibilidades de ejercer un papel central para enfrentar las incertidumbres y riesgos que la sociedad mexicana tiene por adelante. Tanto las demandas internas de cohesión social de la sociedad mexicana y de una correspondiente integración mundial adecuada a la internacionalización de los mercados, depende de la redefinición de la escuela y el conocimiento real de quienes son los estudiantes que la demandan, en función de la construcción de su propio futuro o su proyecto de subjetividad.

Soledad y máscaras

Retomando el fundamental ensayo El laberinto de la soledad, que Octavio Paz escribió en 1950, es posible lograr la comprensión histórica 
de dos momentos cruciales para México: la Independencia (1810) y la Revolución (1910) y desde allí tratar de entender cuales son las claves de ese pasado, soledades y máscaras, que aun persisten en la realidad del 2010. De alguna manera, Paz señala las dificultades que genera un proyecto de nación política cuando se olvida la realidad de la nación cultural.

En México, al igual que en otros lugares en que los pueblos lograban independizarse de España, señala Paz (2010, p. 133), "las nuevas repúblicas fueron inventadas por necesidades políticas y militares del momento (y) los rasgos nacionales se fueron formando más tarde; en muchos casos, no son sino consecuencia de la prédica nacionalista de los gobiernos”. Si bien el propósito de lograr la Independencia de la corona española, partía de un fuerte interés por parte de los criollos por liberarse del control económico y político de España, sin embargo en el discurso de los independentistas no aparece la idea de cambiar la estructura social existente. Es así que en el inicio del movimiento de Independencia la preocupación por construir una nación está ausente. Serán los liberales quiénes finalmente incorporen esta idea a su proyecto político y, en el último tercio del siglo XIX, toman a su cargo la tarea de construir el Estado-nación. Pero cuando los liberales inventan México lo hacen negando su historia: la de la herencia española y la del pasado indígena. Es el proyecto de una minoría que impone su esquema al resto de la población (Paz, op. cit.).

El liberalismo mexicano es una crítica al orden antiguo y una apuesta al futuro. Su proyecto se afirma en los postulados universales de la igualdad y la libertad de los hombres. Pero estas son ideas abstractas sin contenido histórico, útiles tal vez para dar origen a la nación política, pero resultan ser ideas inaplicables y por lo tanto vacías de sentido para incluir a la nación cultural. Afirman al hombre al afirmar la igualdad de todos ante la ley, pero ignoran la realidad social en la que se encuentra México al final del siglo XIX. ${ }^{3}$ El liberalismo olvida que "una nación se constituye (...) por la validez de un proyecto histórico capaz de mover voluntades dispersas y dar unidad y trascendencia al esfuerzo solitario" (idem, ibid., p. 139). Piensan, estos liberales, que basta con decretar nuevas leyes para que la realidad se transforme, pero la realidad resultó ser muy persistente. Sostienen ideas libertarias que "enmascaran la realidad en lugar de desnudarla y expresarla” (p. 131). 
Se busca constituir una burguesía fuerte pero se restauran los privilegios y surge una aristocracia latifundista. Y entonces la república se queda sin base social (Paz, op. cit., p. 140). Es así como el gran proyecto histórico mediante el cual México "se funda a sí mismo como nación destinada a realizarse en ciertas verdades universales, queda reducido a sueño y utopía" (idem, ibid., p. 145), al tiempo que posterga en la pobreza y "sumerge en la soledad" a la mayoría del pueblo mexicano.

Con agudeza, Paz sostiene que "el pueblo rehúsa (...) todo esquema propuesto desde fuera y sin relación profunda con su ser, y se vuelve sobre sí mismo (...): está solo" (op. cit., p. 160). La soledad es un sentimiento de vacío, es la nostalgia de un todo del que ya no se forma parte. La soledad "tiene el doble significado de la ruptura con un mundo y la tentativa de crear otro" (p. 222). La soledad es la no resolución del conflicto con el pasado, y la propuesta de un presente que se construye desconociendo la realidad.

\section{Educación, ¿palabra mágica?}

La Revolución Mexicana de 1910 es un hecho que irrumpe en la historia como una verdadera revelación del ser mexicano; "desnuda de doctrinas previas, ajenas o propias, (...) será una explosión de la realidad y una búsqueda a tientas de la doctrina universal que la justifique y la inserte en la historia de América y en la del mundo" (Paz, 2010, p. 153).

En México, el inicio de un sistema educativo moderno debe ubicarse en 1921, cuando ya concluida la lucha armada de la Revolución Mexicana (1910-1917). Las ideas fundacionales del sistema educativo se articulan a partir de la necesidad de establecer un proyecto que incluyera a todos los sectores sociales, especialmente a los campesinos empobrecidos que habían participado en la lucha armada durante la Revolución, así como a los pueblos indígenas dispersos en el vasto territorio nacional y portadores de una cultura ancestral.

El proyecto liberal de nación se sustentó en la idea de una ciudadanía universal, basada en la concepción de que todos los individuos son libres e iguales, pero redujo la ciudadanía a un mero estatus legal. Consideraban a los indígenas como un lastre en su intento de llevar a cabo un proceso civilizador que permitiría hacer avanzar a la nación. El proyecto surge como una nación integrada, pero esta visión de la sociedad 
políticamente integrada, al omitir a los grupos indígenas, permitió que perduraran las relaciones de asimetría ya presentes en el proceso de conquista y colonización.

Aun cuando la educación formó parte de las preocupaciones de quienes construyeron en las últimas décadas del siglo XIX al Estado-nación mexicano, la escuela creada por ellos fue una escuela dirigida especialmente a las clases medias urbanas. Esta escuela no estaba pensada para la población indígena, la cual quedó marginada del proyecto educativo. En igual circunstancia de no incorporación al proyecto educativo liberal estuvieron los campesinos pobres, si bien ellos no fueron objeto de discriminación en su potencial para aprender o el papel que les tocaba jugar en la naciente sociedad mexicana (Loyo, 2006).

En mayo de 1911, pocos meses después del estallido de la Revolución, se promulgó la Ley de Instrucción Rudimentaria, destinada principalmente a reglamentar la educación dirigida a los indígenas de cualquier edad. Tenía como máximo una duración de dos cursos anuales y no era obligatoria (Espinosa, 2002). Recuperar el debate que en su momento suscitó esta Ley abre la posibilidad de comprender cómo se va constituyendo el concepto de nación y ciudadanía, atravesado por la idea de civilización, y permite comprobar como algunos intelectuales de aquella época justificaban la no incorporación de los sectores indígenas a las escuelas a partir del argumento de la imposibilidad de civilizar a los niños con este origen étnico.

En oposición al proyecto liberal, el de la Revolución es un proyecto incluyente en el cual "predominó una visión antropológica y cultural del país, donde territorio y población serían fundamentales en la construcción del carácter nacional" (Lemperiére, citado por Singüenza, 2010, p. 10). Esta visión orgánica y concreta sobre el quehacer educativo de alguna manera se oponía al proyecto de los liberales basado en principios abstractos: libertad e igualdad.

Tres son los principios que distinguen a esta nueva propuesta: la comprensión clara que la educación tiene que recuperar y reelaborar los sentidos históricos de la nación; la necesidad urgente de educar a todos, en un proyecto inclusivo que se orienta especialmente hacia los campesinos e indígenas; y la responsabilidad del Estado en dar cumplimiento a estos objetivos que se concretan con la promulgación del artículo $3^{\circ}$ de la Constitución de 1917, ${ }^{4}$ relativo a la educación pública y gratuita (Paz, 
2010). El período que abarca de 1921 a 1940 representa una etapa de impulso a la educación rural y abarca distintos momentos: la escuela rural, las misiones culturales, los centros culturales, las casas del pueblo y la educación socialista (Espinosa, 2002).

El proceso de construcción nacional que se estimuló a partir de la Revolución recurrió al mestizaje para articular el nuevo proyecto de nación. Sostenía la igualdad de las razas y la validez de todas las culturas, aunque reconocía la importancia del mestizo en la cultura nacional. Dicha concepción "propició el desarrollo de una mitología que fortaleció en gran parte el nacionalismo oficial durante el siglo pasado, el cual recuperó elementos del liberalismo democrático al tiempo que construyó un Estado corporativista y proteccionista" (Lomnitz, 1993, p. 192).

La escuela primaria, con el aporte de la escuela rural impulsada por la Secretaría de la Educación Pública (SEP) durante estos veinte años, había cumplido con la necesidad de implementar una educación que partiera de las condiciones y necesidades reales del país. Sin embargo, el problema del analfabetismo seguía siendo grave: para 1940 el 54,04\% de la población mayor de diez años era analfabeta. (Espinosa, 2002).

\section{La escuela de la Unidad Nacional: innovación y desencanto}

El agotamiento del proyecto educativo que surge de la Revolución, que prescribía la conformación de una identidad colectiva y la integración social mediante la participación política y la ciudadanía, demuestra sus deficiencias cuando nos informamos sobre sus modestos logros. Si recogemos los aportes de la investigación educativa en el país, tal como lo hizo, M. Bazdresch, ${ }^{5}$ nos daremos cuenta de esa situación. Las oportunidades creadas por las políticas educativas del país no lograron coadyuvar a la disminución de la desigualdad y a promover una integración más significativa entre los mexicanos. Los datos que se presentan indican que la cobertura y la calidad de la educación se vinculan con la condición de pobres.

La información muestra que el proyecto revolucionario relativo a la educación logra apenas a medias promover una mejoría en las condiciones materiales de los mexicanos y se frustra en la tentativa de profundizar la cohesión social cuando se percibe que los indígenas y los marginados no son contemplados con oportunidades educativas. 
La preocupación por la "unidad nacional" y por la industrialización y urbanización del país hizo perder de vista, una vez más, la diversidad cultural de la población. En 1941 se promulga la Ley General de Educación en que se establecen los nuevos lineamientos (Espinosa, 2002). Con esta nueva ley se busca una educación uniforme para todas las regiones del país, tanto el campo como la ciudad se regirían por los mismos planes. De esta manera la educación rural quedó integrada a la educación urbana, olvidándose los proyectos anteriores.

La filosofía educativa de esta propuesta es la misma que formula, en 1944, Jaime Torres Bodet, quien sostenía “(...) que la escuela rural no (debía preparar) campesinos sino ciudadanos mexicanos. Todos los alumnos, cualquiera que fuese la escuela a la que asistieran, contaban con la misma instrucción fundamental y podrían vivir en cualquier parte con la misma facilidad" (Bodet, citado por Espinosa, 2002, p. 21). Además se sostenía que frente al rápido crecimiento industrial y comercial que en ese momento se daba en el país, la escuela rural no había sido capaz de adaptarse a estos cambios.

Pero a finales de los años cincuentas se tiene claro que la unificación de los planes de la enseñanza urbana y rural había desvirtuado los fines específicos de ambas instituciones y no se había logrado un avance significativo en la cobertura de la educación básica. En 1958 el presidente de la República reconoce que había tres millones de niños en edad escolar sin escuela, además de otros problemas importantes como la falta de maestros adecuadamente formados y la carencia de suficientes edificios escolares. Frente a esta delicada situación de la educación básica del país, en 1959 se formula dos políticas que tendrán un gran impacto en el sistema educativo: Plan Nacional para la Expansión y el Mejoramiento de la Educación Primaria y la creación de la Comisión de los Libros de Texto Gratuitos.

El mencionado plan nacional, conocido como Plan de Once Años, pretendía que en el año 1970, o sea, once años después de su puesta en marcha, pudiera garantizarse el acceso a la escuela primaria a todos los niños en edad escolar. El logro de este objetivo recién se realiza en 1980, una década después de lo planeado.

En cuanto a la publicación y distribución entre los alumnos de todas las regiones del país de los libros de texto gratuito fue elemento fundamental en la consolidación del civismo y de la identidad nacional. 
El libro de texto gratuito es la presencia del programa oficial e institucional en el salón de clase. A partir de su creación impactó significativamente el proceso de enseñanza-aprendizaje, en especial las ediciones de Lengua Nacional e Historia, cuyos contenidos, la reiteración de los mismos y su respaldo en imágenes fortalecieron el proceso de construcción de la identidad nacional (Singüenza, 2010).

El sistema de educación pública va revelarse, a nivel de las asignaciones presupuestarias nacionales, impotente en la disputa por los recursos económicos necesarios para una operación adecuada, pero además en relación a sus intentos de construir ciudadanía y cohesión no alcanza a enfrentarse a comportamientos políticos clientelares que se desarrollan y se fortalecen al cobijo del partido político único vigente por muchos años en el país. La preeminencia de la burocratización en la operación del sistema educativo y la permanencia de un fuerte corporativismo al interior del Sindicato Nacional de los Trabajadores de la Educación (SNTE) impiden flexibilidades e innovaciones necesarias a las políticas educativas y sus correspondientes tareas en todos los niveles de operación del sistema.

La pluralidad en la concepción y sentido de la educación se percibe mermada y el valor que se puede atribuir a una formación autónoma y crítica ocurre casi siempre al azar.

\section{La nación pluricultural}

En los países de América Latina, la multiculturalidad es el resultado de los procesos de conquista y colonización que generaron discriminación y exclusión de los pueblos indígenas. Sin embargo el objetivo de la integración no se logró, dado que el modelo ignoró las diferencias culturales de los distintos grupos sociales, especialmente los indígenas. De alguna manera el planteamiento que hoy se hace acerca de la interculturalidad busca superar estas omisiones originadas en la antigua visión de la sociedad como un "crisol de culturas", y/o cuestionando también la visión de la nación como la suma de distintas identidades y culturas habitando un mismo espacio, visión desde la cual ocurren severas formas de discriminación social y económica, particularmente hacia los grupos indígenas.

El reconocimiento de la pluralidad étnica considera la problemática de identidad colectiva y de desarrollo de la cohesión social, pero es 
entendido de varías maneras por diferentes autores. La producción teórica gira en torno al tema del reconocimiento de las diversas identidades culturales y el problema de la convivencia.

En la realidad social actual, caracterizada por tres claras tendencias conectadas - como la homogenización cultural que acompaña los procesos de globalización, las propuestas de resistencia cultural a nivel local y una vigorización de procesos de individuación -, se percibe el debilitamiento y la disminución del papel del Estado en sus pretensiones, anteriormente legítimas, de construcción de una nación cultural homogénea. Estas corrientes de pensamiento se van a reflejar en los programas de los organismos internacionales, abriendo camino para su aceptación al interior del país. Se advierte entonces una situación social novedosa e importante en términos de convivencia, o sea, "la existencia, en el interior de una comunidad política, de diferentes grupos socio-culturales que desarrollan prácticas, relaciones, tradiciones, valores e identidades culturales (individuales y colectivas) distintas y propias y que presentan reivindicaciones de reconocimiento específicos" (Gurza Lavalle, 2006, p. 249).

Antes de reseñar la propuesta para el desarrollo de una educación intercultural que se inicia en México en el año de 2001, es importante discurrir sobre las variaciones que se presentan en la definición de conceptos centrales como pluriculturalidad, multiculturalidad e interculturalidad, todos referidos a la coexistencia de diversas comunidades culturales en un mismo territorio nacionalmente definido. La identificación de posiciones nos proporcionará mayor claridad para ubicar y entender la propuesta de educación intercultural en México.

Trataremos en primer término de autores que niegan de alguna forma la potencialidad de esos conceptos como rutas para una integración respetuosa de la diferencia con los necesarios rasgos emancipatorios. Entre ellos están Rancière, Badiou y Zizek. Todos ellos plantean la cuestión desde una perspectiva macro que, por supuesto, incluye y considera críticamente la dinámica de la sociedad capitalista en que vivimos.

En una exposición muy sintética, señalaremos que Jacques Rancière habla de una emancipación que presupone la igualdad de todos. Sin esta premisa que se refiere a "cualquiera", incluso a "los sin parte", no ocurre lo que llama "política".

A partir de una entrevista con el autor mencionado, sobre su libro Odio a la democracia, Fernández-Savater (2009, p. 9) señala: "Rancière 
rompe con la alternativa dominante entre el poder de las oligarquías políticas y económicas o el de los ancestros y las etnias, definiendo la democracia como el poder de cualquiera”. En la misma ocasión, Rancière (2009, p. 3) expresa:

(...) Mi idea es que la política comienza cuando nacen sujetos políticos que ya no definen ninguna particularidad social, sino que definen, por el contrario, el poder de "cualquiera" (...). La emancipación política no consiste en las constituciones, las leyes, los modos de gobierno, sino que es la creación de una especie de mundo común, que es además un mundo de la capacidad común.

Según este autor, las particularidades sociales cuentan menos para la emancipación y convivencia política que la aceptación de la igualdad encarnada en "cualquiera" o en la capacidad común. A partir de ahí y extrapolando el pensamiento de Rancière hacia la cuestión de la multiculturalidad, la definición de un futuro viable tiene mas que ver con lo común (la igualdad) entre los individuos y no tanto con las diferencias o diversidad. Esa posición va contra-corriente a las visiones de un devenir que otorga centralidad desproporcionada a las diferencias frente a la importancia del presupuesto de la igualdad entre los sujetos. Muchas de las propuestas educativas, preocupadas por la interculturalidad, con frecuencia establecen sus prioridades fincadas en la diferencias y en la valorización de la diversidad.

Al nombrar el otro y las diferencias, conviene mencionar la reflexión que desarrolla Badiou (2007, p. 15) al respecto, aun cuando se refiere a la diversidad cultural de la migración que ocurre en Europa:

El hecho de que mi relación con los extranjeros sea una relación activa, organizada y militante, consolida justamente mi idea de que el problema principal no remite sólo a la cuestión del otro, de la diferencia cultural, etc., sino que afecta sobre todo a lo que tenemos en común y a las batallas políticas que podamos librar juntos, no solamente para ellos o por ellos, sino también para y por nosotros. Hay un punto donde estos caminos pueden cruzarse, pueden encontrarse y organizarse. Y eso es lo que refuerza y constituye la base material de mi convicción de que de esta forma podemos forjar una verdadera trayectoria política.

En este caso parece ser que lo común es central en la formación de sujetos o subjetividades políticas y quizás la emancipación, condición que por supuesto tendría sus reflejos en la educación y la escuela. 
Un otro autor que piensa la diversidad desde una visión que abarca el sistema social como un todo es Zizek. Para el autor, la celebración o exacerbación de las diferencias o diversidades vinculadas con el frecuente discurso de la tolerancia al interior del pensamiento multiculturalista vuelven a este una propuesta ya mediada por una orientación hacia la integración y no hacia la conservación o "sobrevivencia de "grupos primordiales". Para Zizek, el multiculturalismo no representa un sector de resistencia frente al capitalismo, sino todo lo contrario. No es un movimiento de defensa de la diferencia que al final encuentre el camino disidente hacia un "afuera del sistema", considera que el multiculturalismo propone también un regreso a las identidades comunitarias... sin embargo tal regreso está ya mediado por el movimiento de integración. Lo que Zizek está señalando es que la regresión a tales comunidades sólo tiene lugar en el contexto capitalista, y en tanto forma parte de la celebración de la diferencia vuelve, nuevamente a quedar atrapada en la integración (Hernández Reyna, 2007).

La literatura poscolonialista, que en su mayor parte se desarrolla en territorios que estuvieron bajo dominio ingles, aporta una visión distinta de la multiculturalidad: las diversas culturas no son construcciones estáticas e inamovibles. Esta postura implica entonces en negociaciones constantes entre unidades culturales bajo la lógica de la representación "como un momento constitutivo de relaciones sociales" y no en un simple reconocimiento político de culturas preconstituidas. "Se busca una renovación cultural y una ruptura con clichés y estereotipos" (Gurza Lavalle, 2006, p. 259). Estas posiciones inhiben los fundamentalismos.

Por lo anterior vemos que el reconocimiento de la pluralidad étnica, que considera la problemática de la identidad colectiva y del desarrollo de la cohesión social en las sociedades, es entendido de varias maneras con resultados polémicos. En este texto trataremos principalmente el tema de la redefinición de la educación y la institución escolar frente a una diversidad étnica plenamente reconocida en el contexto actual. ${ }^{7}$ En México como en América Latina en general, las políticas educativas que recién emergen, derivadas de la aceptación de una pluriculturalidad, van a considerar la interculturalidad sobretodo como una condición de convivencia y de derechos que deben ser alcanzados. La escuela, y sus tareas de formación en todos sus niveles, estaría encargada de sostener el logro de esas propuestas. Es pertinente precisar la gestación de esas nuevas metas educativas. A partir de lo que se expuso anteriormente sobre las 
diversas perspectivas que acompañan la reflexión sobre multiculturalidad, se podría decir que la posición que advertimos en México sobre educación se acerca a los elementos presentes en el aporte de Ranciére respecto a una igualdad preexistente entre los individuos y también de alguna manera refleja el pensamiento poscolonialista, que enfatiza la no domesticación de las culturas originarias y la negociación permanente para evitar el aprisionamiento y dar continuidad a la creación cultural.

La visión mexicana de la sociedad políticamente integrada, al omitir las diferencias de los grupos indígenas, permitió que perduraran las relaciones de asimetría ya presentes en los procesos de conquista y colonización. Gasché (2002) hace un interesante análisis de las condiciones objetivas de estas desigualdades y señala, entre otras, la ausencia de reconocimiento de las instituciones, prácticas y valores de un pueblo determinado, cuando sus conocimientos y tradiciones no se transmiten en la escuela. Pero también destaca como un factor importante en la construcción de estas desigualdades: los mecanismos subjetivos a partir de los cuales algunos indígenas niegan, rechazan o desprecian su propia sociedad y cultura. Este fenómeno tiene como uno de sus fundamentos las expresiones de negación e incluso de abierto rechazo de la sociedad general a las aspiraciones y valores de sus etnias. La educación intercultural tendrá que trabajar en estos dos niveles, en la eliminación de los prejuicios racistas de la población no indígena y en la afirmación de los derechos y aspiraciones de los pueblos indígenas, de modo tal que se establezcan relaciones igualitarias entre ambos. La interculturalidad debe abordarse desde la perspectiva de los derechos de los pueblos originarios sin perder de vista la situación de pobreza ancestral en que se encuentran.

La definición de interculturalidad que formula García Canclini (2004, p. 28) resulta bastante precisa para comprender el cambio que es necesario introducir en las relaciones interculturales:

De un mundo multicultural - yuxtaposición de etnias o grupos en una ciudad o nación - pasamos a otro intercultural globalizado. Bajo concepciones multiculturales se admite la diversidad de culturas, subrayando la diferencia y proponiendo políticas relativistas de respeto, que a menudo refuerzan la segregación. En cambio, interculturalidad remite a la confrontación y el entrelazamiento, a lo que sucede cuando los grupos entran en relaciones e intercambios. Ambos términos implican dos modos de producción social: multiculturalidad supone aceptación de lo heterogéneo; 
interculturalidad implica que los diferentes son lo que son en relaciones de negociación, conflicto y préstamos recíprocos.

Si bien se puede reconocer a la interculturalidad como un principio de convivencia, tiene simultáneamente que ser considerado como un proyecto social incluyente.

Antes de trazar algunas características de la propuesta de educación intercultural en México, nos parece interesante relacionarla nuevamente con la visión de una latinidad que fue propuesta como una ruta homogenizadora de las sociedades latinoamericanas. La idea de interculturalidad se opone a la homogenización cultural en términos de una latinidad de origen europeo, que elaborada externamente y aisladamente de la realidad de América Latina, no logró una integración interna y externa en esas naciones. La latinidad que expresaba un modelo civilizatorio occidental (europeo) en una "versión latina", que pretendía aglomerar territorios y poblaciones diversas en cultura e historia: unos plenamente latinos, los europeos y los demás en tránsito hacia esa condición sociocultural dominada o liderada por los primeros.

Pero la idea de tutela política y moral de la metrópolis y posteriormente el nacionalismo anclado en la valoración del mestizaje no logran ser mas que una "construcción discursiva que, según Gurza Lavalle (2006, p. 265), "opera como máscara ideológica que esconde la real desigualdad de oportunidades entre los varios grupos socio-culturales que comparten el territorio del país".

Posteriormente, la reivindicación de justicia social sobrepasa a las ideas de ciudadanía política o las categorías de campesinos u obreros: se introducen con gran fuerza elementos vinculados a la identidad étnica e incluso racial. La conformación como una nación cultural se redefine y se busca encontrar rutas de autoreconocimiento y de expresión de una identidad que permitan superar la condición de aislamiento, invisibilidad e indefinición que hasta ahora han sido parte de la historia. Tal condición es con frecuencia nombrada como la soledad de nuestras naciones. Sin una construcción socio-política auténtica, nos desconocemos entre nosotros mismos y somos desconocidos por los demás países. De eso se trata la soledad.

La propuesta reciente de la educación intercultural en México recoge los planteos anteriores y define una escuela que asume la tarea de 
coadyuvar una transformación socio-política que implica y alcanza todos sus miembros. En el próximo apartado se analizará con detalle tal propuesta y su desarrollo hasta la fecha.

\section{La educación intercultural en México}

Desde la perspectiva del reconocimiento de los derechos de los pueblos indígenas, especialmente los referidos a sus culturas y lenguas, México emprendió una significativa reestructuración de legislación que abarcó incluso modificaciones a la propia Constitución nacional. Precisamente en 1992, al cumplirse quinientos años de la Conquista o del Encuentro de dos Civilizaciones, se incorpora en la Constitución el reconocimiento de México como país multicultural y plurilingüe. ${ }^{8} \mathrm{Com}$ plementando esta reforma constitucional, que permitió superar la visión de la cultura única que durante casi un siglo y medio se plasmó en la Carta Magna, en los siguientes años se modificaron o crearon leyes y decretos que fueron consolidando, al menos en los aspectos jurídicos, esta perspectiva intercultural.

Varios organismos internacionales también promovieron e impulsaron, a través de la publicación de diversos documentos, este esfuerzo de reconocimiento de los derechos de los grupos originarios. Dentro de estos documentos destaca el elaborado en 1989 por la Organización Internacional del Trabajo (ОIT), titulado Convenio sobre pueblos indigenas y tribales en paises independientes. Este convenio fue ratificado por México en 1990. En el apartado IV del Convenio se enuncian los derechos educativos de los pueblos originarios. Entre otros menciona: el derecho a la educación de los pueblos indígenas "en todos los niveles educativos... en pie de igualdad con el resto de la comunidad nacional"; la necesidad que los programas destinados a estos grupos incluyan "su historia, sus conocimientos y técnicas, sus sistemas de valores y todas las demás aspiraciones sociales, económicas y culturales"; el derecho a aprender a leer y escribir en su propia lengua y a dominar la lengua nacional; el derecho a crear sus propias instituciones educativas y a formar a sus maestros.

La propuesta de educación intercultural se apoya en tres principios básicos: 1) la ciudadanía, que garantiza la igualdad real y efectiva de derechos, responsabilidades y oportunidades; 2) el derecho a la diferencia, que significa el respeto a la identidad y a las expresiones 
socioculturales; y 3) la unidad en la diversidad, que se refiere a una unidad nacional voluntaria y construida por todos (Menchú, 2002).

A partir de la creación de la Coordinación General de Educación Intercultural - Bilingue, en 2001, en México se ha estado trabajando en la formulación de un proyecto que trascienda el nivel de la educación primaria, en el que siempre se situó a la educación indígena, para garantizar las oportunidades de educación en todos los niveles en igualdad de condiciones. Se crean instituciones educativas "indígenas de nivel superior". Esta propuesta de educación intercultural se propone corregir equivocaciones en el desarrollo socio-cultural del país en aras de recuperar las posibilidades de cohesión social muy dañada por las asimetrías socio económicas que, desde siempre, prevalecen en la realidad. Desde el ámbito educativo por si mismo, es harto difícil introducir transformaciones a nivel estructural. De cierta manera la propuesta de interculturalidad en la educación, al no alcanzar otros niveles, se ve reducida en su éxito. Así, todavía, no se incorporan a la Constitución Mexicana demandas básicas de los grupos originarios como son la autonomía y el derecho colectivo, que serían reconocimientos formales de autodeterminación del futuro de sus comunidades. Sin estos elementos la interculturalidad como propuesta de convivencia no se alcanza a través de la escuela. Sin embargo, la formalización de una política educativa intercultural ha seguido adelante e intenta establecerse como un eje importante en el desarrollo educativo del país.

\section{Los obstáculos}

El contexto en que debe desarrollarse esta propuesta es por demás adverso. Uno de los grandes obstáculos es la situación de marginación y pobreza en la que encuentran los pueblos indígenas. Un problema ancestral que persiste desde la conquista y que se ha acentuado con las recientes políticas pautadas por el mercado. Las reducciones en el gasto público han incrementado la discriminación financiera que siempre afectó a las poblaciones indígenas. El gasto en educación para estas poblaciones siempre ha sido inferior al que reciben otros sectores poblacionales. Las escuelas a nivel básico no han logrado operar las propuestas interculturales de manera satisfactoria. Los índices de desarrollo educativo son incuestionables: la retención y egreso de los ciclos escolares es restringida, no se han logrado habilidades adecuadas de lenguaje, pues no 
leen ni escriben en el idioma original y son poco aptos en el español. Además los maestros frecuentemente no son indígenas y cuando lo son cargan con lastres de baja autoestima respecto a su propia cultura y parecen haber internalizado el racismo. Con frecuencia se experimenta una asimetría valorativa que constituye la devaluación de lo propio en una estrategia de integridad psicológica ante el trato denigrante y la falta de dignidad en la relación intercultural (Schmelkels, 2001).

El objetivo de una educación intercultural y de la escuela que le corresponde es comprometer a toda la población en la medida que pretendemos una relación simétrica entre las diversas culturas.

Sin embargo, por lo que se ha dicho anteriormente, es obligado reconocer que la proposición de interculturalidad, que es innovadora en el escenario de las políticas educativas en México, no obtuvo hasta ahora el éxito esperado y necesario para cumplir con su objetivo mas trascendente, que es el de corregir la presencia de la discriminación racial, reducir las asimetrías valorativas y trazar una vía hacia una convivencia social mas respetuosa, donde las posibilidades de reconstruir la sociabilidad y las identidades sean reales. La escuela mexicana está llamada a transitar por otros caminos para encontrarse con nuevos alumnos.

\section{Notas}

1. Según el censo del año 2000, la población total de México era 97.483 .412 personas. La proporción de población indígena es de $10 \%$ a $14 \%$, según las diferentes regiones del país, alcanzando los 10.189 .514 de individuos a nivel nacional. El número de lenguas nacionales, así son reconocidas actualmente, es de 62 idiomas.

2. La mención a la soledad latinoamericana como característica de la historia de la región la hace también Gabriel García Marquez, en su discurso de recibimiento del premio Nobel de Literatura en 1982.

3. Hacia finales del siglo XIx la casi totalidad de la población rural se encontraba en condiciones de pobreza, cual significaba más de dos tercios de la población total, pues de acuerdo con el censo de 1900 solo el 28,2\% de la población total vivía en zonas urbanas (localidades con más de 2.500 personas).

4. Artículo $3^{\circ}$ de la Constitución Política de los Estados Unidos Mexicanos: "Todo individuo tiene derecho a recibir educación. (...) Será democrática (...) Será nacional (...). Contribuirá a la mejor convivencia humana (...). La educación primaria será obligatoria (...). Toda la educación que el Estado imparta será gratuita”.

5. Los pobres desde la educación son:

“- Los niños y niñas que no asisten a la escuela, y especialmente si viven en áreas rurales, en comunidades de pocos habitantes (menos de 100), o en zonas urbanas marginadas. 
- Las niñas de mas de 12 años, especialmente si viven en zona rural o marginada urbana.

- Los niños indígenas del país, en su mayoría.

- Los indígenas en general.

- Los analfabetos, totales y funcionales, del país.

- Los niños y jóvenes desertores, especialmente los urbanos.

- Los niños escolares con deficiente aprovechamiento escolar, y que deben repetir cursos.

- Los jóvenes y adultos rezagados por edad en la terminación de la primaria.

- Los niños y jóvenes que, habiendo culminado los ciclos escolares con éxito, no pueden demostrar la adquisición de las competencias culturales básicas" (Bazdresch, 2001, p. 78).

6. Ver Gurza Lavalle (2006, p. 249). El autor se refiere al concepto de interculturalidad como una realidad o una problemática y no a uno "modelo específico de convivencia social".

7. Este documento se centra en la cuestión de la diversidad étnica y el correspondiente racismo que se establece en México desde la Conquista en 1519. Sin embargo, actualmente, sería importante señalar la transferencia de la discriminación hacia poblaciones o subculturas urbanas que, marginadas por la exclusión, también lo son por "los rasgos fisonómicos" e incluso por sus costumbres vigentes, penetrados todavía por particularidades remanentes de culturas originales.

8. Sin embargo, aún no se incorporan a la Constitución Mexicana demandas básicas de los grupos originarios como son la autonomía y el derecho colectivo.

\section{Referências}

BADIOU, A. Un nosotros extranjero. Entrevista de Amador Fernández Savater. Revista Minerva, Madrid, n. 5, 2007. Disponível em: $<$ www.circulobellasartes.com/mt_visor.php?id=4834>

BAUDELOT, C.; LECLERQ, F. Los efectos de la educación. Buenos Aires: Del Estante, 2008.

BAZDRECH, P.M. Educación y pobreza: una relación conflictiva. In: Ziccardi, A. (Coord.). Pobreza, desigualdad social y ciudadania: los limites de las políticas sociales en América Latina. Buenos Aires: CLACso, 2001. p. 65-81.

CASTRO, I. Los procesos socio-culturales y la educación. In: ENCUENTRO INTERNACIONAL DE INVESTIGADORES DE LA RED EDUCACIÓN, CULTURA Y POLÍTICA EN AMÉRICA LATINA, 6., 2010, Puebla. Anales... Puebla, 2010.

COSTA, S.; GURZA LAVALLE, A. Cohesión social y coexistencia intercultural en América Latina. In: CotLer, J. (Coord.). La cohesión 
social en América Latina y en la Unión Europea. Lima: IEP; OBreAL, 2006. (América Problema n. 19). p. 247-280.

DUBET, F.; MARTUCCELLI, D. En la escuela: sociología de la experiencia escolar. Madrid: Losada, 1998.

ESPINOSA, C.M.E. La escuela primaria en el siglo Xx: consolidación de un invento. In: DICCIONARIO de historia de la educación en México. México, DF: UNAM; CIESAS; CONACYT, 2002.

FERNÁNDEZ SAVATER, A. Entrevista a Jacques Rancière. El País, Madrid, 9 sept. 2009.

GARCÍA CANCLINI, N. Diferentes, desiguales, desconectados. Buenos Aires: GEDISA, 2004.

GASCHÉ, J. Criterios e instrumentos de una pedagogía intercultural. Relaciones, México, DF, v. 23, n. 91, p. 193-234, 2002.

GURZA LAVALLE, A. Cidadania, igualdade e diferença. Lua Nova, São Paulo, n. 59, p. 74-93, 2003.

HERNÁNDEZ REYNA, M. Problemas para una teoría de la educación intercultural en México. Trabalho apresentado no Congresso Internacional de Filosofía y Educación en nuestra América, Universidad Nacional de Cuyo, oct. 2006.

LOMNITZ, C. Hacia una antropología de la nacionalidad mexicana. Revista Mexicana de Sociología, México, DF, v. 55, n. 2, p. 169-195, abr./jun. 1993.

LOYO, E. La educación de los indígenas: polémica en torno a la ley de Escuelas de Instrucción Rudimentaria (1911-1917). In: MorenoBonett, M.; GonzÁlez, M. (Coord.). La génesis de los derechos humanos en México. México, DF: UnAM, 2006. p. 359-376.

MENCHU, R. El sueño de una sociedad intercultural. In: IMBERNÓN, F. (Coord.). Cinco ciudadanias para una nueva educación. Barcelona: Graó, 2002. p. 63-81.

MIGNOLO, W. La idea de América Latina. Buenos Aires: GedisA, 2007. 
PANI, A. La instrucción rudimentaria en la república. México, DF: Secretaria de Instrucción Pública y Bellas Artes, 1912.

PAZ, O. El laberinto de la soledad. 4. ed. México, DF: Fondo de Cultura Económica, 2010. (1 $1^{\text {a }}$ edición se publicó en el año 1950, en Cuadernos Americanos).

RANCIÈRE, J. La democracia es el poder de cualquiera. Entrevista de Amador Fernández Savater. El Pais, Madrid, p. 9, 1 sept. 2009.

SCHMELKES, S. Intercultura y educación de jóvenes y adultos. Revista Interamericana de Educación de Adultos, Patzcuaro, n. especial, p. 27-36, 2001.

SCHMELKES, S. La interculturalidad en la educación básica. Revista PRELAC/UNESCO, Santiago, n. 3, p. 120-127, dic. 2006.

SIGÜENZA, S. Se levanta en el mástil mi bandera... reflexiones en torno al nacionalismo mexicano. CPU-e, Revista de Investigación Educativa, n. 11, jul/dic. 2010. Disponível em: <http://www.uv.mx/ cpue/num11/inves/siguenza-nacionalismo.html>. Acesso em: 25 jul. 2010 .

ZIZEK, S. Multiculturalismo o la lógica cultural del capitalismo multinacional. In: JAMESON, F,; ZIZEK, S. Estudios culturales: reflexiones sobre el multiculturalismo. Buenos Aires: Paidós, 1998. p. 137-186.

Recebido em agosto de 2010. Aprovado em outubro 2010. 